\title{
Study on the Intellectual Property Protection Mechanism in the Technical Innovation of Enterprise
}

\author{
Yurong Chen \& Weixing Wang \\ School of Economics \& Management, Changzhou University, Changzhou 213164, China \\ E-mail: cyrpzh@126.com
}

The research is supported by the "Study on the Enterprise Technical Innovation Mechanism and the Protection Mechanism Based on the Intellectual Property Strategy" of the Arts Development Fund of 2010 of Changzhou University (No. JW201008) and the "Study on the Enterprise Technical Innovation Mechanism and the Protection Mechanism Based on the Intellectual Property Strategy" of the Jiangsu Provincial Colleges Philosophical and Social Science Research Project of 2010 of Jiangsu Provincial Colleges (No. 2010SJD630002). (Sponsoring information)

\begin{abstract}
Enterprise is the main body of technical innovation, and the main body of the creation, protection, and implementation of intellectual property. The intellectual property protection and management run through the whole process of technical innovation. The problems existing in the intellectual property protection of the innovational results in the enterprise technical innovation are analyzed, and corresponding countermeasures are suggested in this article.
\end{abstract}

Keywords: Technical innovation, Knowledge property, Intangible assets

Technical innovation and intellectual property protection are two important parts to promote the development of modern enterprises. By technical innovation, enterprises could acquire, allocate, and create technical and intellectual resources, cultivate and enhance their core technologies and capacities, and establish their competitive advantages. The intellectual property protection emphasizes that the intellectual assets of the enterprise protected by the laws should not be invaded by others. Innovation is the headspring of intellectual property, and intellectual property protection is the driver of innovation. To cultivate the core competitive ability of enterprise is the key to implement the intellectual property protection of the technical and innovational results for enterprises.

\section{Intellectual property protection promotes the technical innovation of enterprise}

Intellectual property protection is one of basic premises to ensure the rights, capitalization, commercialization, and marketization of the technical and innovational results. The technical and innovational results needs the protection of intellectual property, and the perfection of the intellectual property protection system will largely encourage and drive the technical innovation, and provide a interior drive and a exterior fair competitive and legal environment for the technical innovation, which is very important to promote the technical innovation.

1.1 The intellectual property protection system is the most effective encouragement mechanism of technical innovation

The development history of science, technology, and economy and the experiences of various countries indicate that the intellectual property system uses the legal and economic measures to ensure that the originator could enjoy the exclusive right for his technical and innovational result in certain term by the form of national laws. Without the patentee's permission, others could not use this invention, so the originator could return the investment of the invention and obtain the extra profit by using or allowing others to use this invention. But the acquirement of the extra profit is after the marketization of the technical innovation, and the amount of the extra profit is linked with the market effect of technical innovation, which is like adding the benefit oil to the genius fire.

\subsection{The intellectual property protection system is the legal protection mechanism of technical innovation}

It is better to say that the competition among countries is the economic competition, than say that the competition is the competition of science, technology, and talents, and the essential of the talent competition is the competition of intellectual property, and who possesses independent intellectual property in certain one technical domain will obtain the control right in this domain, and the intellectual property is being one of the most important resources in the world. To promote the development of technical innovation, a fair competitive rule must be established, and a fairly competitive environment must the built. The essential of the intellectual property system is to encourage and establish the fair competition based on technical innovation, and it would 
establish the fairly competitive rule by the patent law, the brand law, the copyright law, and the anti-unfair competition law. At the same time, by the legal form, the intellectual property system will legally protect the patent right, the brand right, and the copyright according to relative laws. For those behaviors disobeying the intellectual property law, various governments all would punish them by the administration form or the judicial form.

\subsection{The intellectual property protection system is the leading mechanism of technical innovation}

The intellectual property system could provide not only powerful drive and effective legal guarantee for technical innovation, but also scientific reference to reasonably allocate technical innovation resources and correctly select the direction and approach of technical innovation. The patent laws in various countries all regulated that the invention and creation applying patent must publish the invention content by sufficient and complete specification in legal term. These up-to-date technical intelligences will be widely diffused in the world. The patent literatures are the historical record of human technical innovation, but the treasure of human intelligent results. Technical innovation staff could know and grasp the level and direction of the up-to-date technical innovation in the world, and select right direction and approach of technical innovation, effectively allocate the resources of technical innovation, enhance the start and level of technical innovation, avoid the waste of human resource, financial resource, and material resource, and create the up-to-date technologies and products on the "giants" shoulders.

\subsection{The intellectual property protection system is the accelerating mechanism of technical innovation industrialization}

Because of the novelty, the practicability, and the creativity, the intellectual property system could ensure that the patentee of the invention has twenty years' protection term in laws, and in this term, the illegal competition will be eliminated, so the implementation of the patent technology is more advantageous than the implementation of other technologies, and the originator can start the company himself, or go to the industrial and mining enterprises with his own patent and transfer the patent with compensation, and many new industries supported by the patent technologies will be gradually formed. The practice has proved that the intellectual property system has been the accelerator of the industrialization of technical innovation.

\section{Technical innovation is the creation activity of intellectual property}

Technical innovation is the process including the research and formation of new invention and creation, the application and implementation of new invention and creation, the commercialization and industrialization diffusion of new technology, and the commercialization of new technical results. In various stages and parts of the enterprise technical innovation, the intellectual property protection is being generated and filtered, and the technical innovation is closely related with the intellectual property protection, and both of them will drive the flourish development of the enterprise in the drastic market competition.

\subsection{The intellectual property protection in the planning and evaluation stage of technical innovation}

The planning and evaluation stage is the start of technical innovation, and it means the innovation subject begin to think the primary consideration, conception, and evaluation about the scientific foreground, the production method, the technical project, and the technical flow under the influence of various innovational factors, and discover valuable new technologies, methods, organizations, and market, and prepare for relative creative activities. In this stage, many creative intellectual activities such as information acquisition, materials induction, market analysis, and value judgment are needed, so large numerous of intellectual properties will occur, such as the actuality and prediction of certain technology by information acquisition and processing, the market report of certain production by the market analysis, and the relative industrial competition trend and profitable foreground by the evaluation and prediction, which all have large commercial values, and some of them could form the intellectual properties such as copyright and commercial secrets, and are very important to confirm the technical object, the product direction, and the competitive strategy for the enterprises in the starting stage.

\subsection{The intellectual property protection in the research and development stage of technical innovation}

By research and development, new product, technologies, and other technical results could be obtained, and these results should be applied and protected by the form of patent, and be saved as the innovation subject's commercial secrets. In addition, innovation subject's all technical materials and research and development result could be protected by the copyright. Except for self-research and development of innovation subject, innovation subject could cooperate with scientific research institutions and colleges, and these activities could produce the intellectual properties such as patent, copyright, and commercial secrete, and the different is that these units would share the rights of intellectual property according to the arrangement and laws. In the cooperation and 
development process, the intellectual property ownership must be confirmed in the innovation, and both parties in the cooperation should sign the contract, confirm the authorship right, the ownership, the application right, and the using right of the results to avoid the intellectual property right disputes. Except for above forms, the intellectual properties will also be produced in the technical introduction and technical trade, and it is also a mode to obtain the intellectual property for modern enterprise.

\subsection{The intellectual property protection in the experiment and trial-production stage of technical innovation}

The generation and commercialization implementation of a new technology need a series of experiments, and before the scale production, the trial-production should be implemented because of the subjective process of the mature process and the production implementation of technology. This process contains the intellectual properties such as the invention and design patent, the copyright, and the technical secret, for example, the certain product obtained by the research and experiment, or the method of manufacturing certain product, and the appearance design products all could be the patents to apply, and the key technologies, the manufacturing methods, and prescriptions could be managed by the form of technical secrets in the nonpublic state, and the technical parameters, the performance explanation, and the design drawings of the primary products formed in this stage could be protected according to the copyright law, and these results could form the intellectual properties which could be protected.

\subsection{The intellectual property protection in the production and distribution stage of technical innovation}

By the research and development and trail production, this technical project and level have entered into the mature stage, and the innovation subject could implement large numbers of commercialization production and distribution, and this stage is the most important formation stage of the intellectual property. The mass-production level and the commercialization level are closely related with the intellectual property management level in this stage. Except for the intellectual properties such as technical knack, copyright, and commercial secretes, the most important thing in this stage is to produce and protect the trademark right. Trademark represents the quality and reputation of the special product in the special enterprise, and it is very important and valuable to develop the market, maintain the reputation, and ensure the distribution for the enterprise. Generally, enterprises will register the trademark for their products in the production and distribution, so in this stage, this important intellectual property, i.e. the trademark, will certainly form.

\subsection{The intellectual property protection in the information diffusion of technical innovation}

Good intellectual property protection environment is propitious to diffuse the results of technical innovation, or else, these technologies should be kept in secrete, but the technologies in secrete are disadvantageous. First, others would not obtain the information, and may repetitively research and develop. Second, once the secret measures are not effective, others will obtain the knowledge by visit, learning, negotiation, and reverse engineering, and the originator will not obtain the extra profit. Third, the secret technology could not compete with the trading of similar technologies to the third party. But the technologies protected by the intellectual property could be published, because the patent right is an exclusive right, and any others could not use it for the production and operation, but the patent technologies could be published under the legal protection, and anyone could check it for the scientific research and enhance the start and speed of scientific research.

\subsection{The intellectual property protection in the asset management of technical innovation}

The result of technical innovation could form the intellectual property by legal registration and authorization, and become the intangible assets to embody the strength of enterprise. Technical innovation could also produce concealed and nonpublic knowledge such as technical secrets, and these innovations belong to the interior knowledge assets, and must be protected by the management of interior knowledge assets.

\section{Intellectual property protection in the technical innovation process}

\subsection{Problems existing in the intellectual property protection of technical innovation process}

\subsubsection{Technical innovation body's ideological cognition is not clear}

Up to now, some technical innovational subjects have not known the intellectual property protection problems clearly in the technical innovational process. For example, they don't know what the intellectual property is, and don't know the intellectual property law, and don't know the intellectual property could be formed in the technical innovational process, and cannot acquire the intellectual property in the technical innovation process, and they don't know and will not protect their intellectual property, and will not and would not protect others' intellectual property. And they will not only ignore the intellectual property in the cultural domain, but also don't emphasize the intellectual property in the decision. 


\subsubsection{The investment of intellectual property protection in the technical innovation process is deficient}

In China, the investments of financial and human resources to protect the intellectual property in the technical innovational process have not adapted the international competition of the drastic technical innovation and intellectual property. There are many relative institutions in foreign countries, but not in China, such as the independent intellectual property court and the self-disciplined industrial intellectual property protection association. The manning quotas in the intellectual property protection institution are still too small, and the technical innovational subjects' investment is too less, including the corresponding investments in the intellectual property management and protection departments. And the senior talents or professional talents directly engaging in the intellectual property protection in the technical innovational subject or relative intellectual property management, agency, and protection institutions are very deficient.

\subsubsection{The agency between technical innovation and intellectual property is weak}

At present, there are few social organizations, institutions, personnel, and service projects providing the intellectual property service between the government department or the judicial department with the intellectual innovational subject or the intellectual property oblige, and the service level is very low. The foreign and domestic intellectual property communication and cooperation whether on the layer of technical innovation subject or the agency institution or on the layer of administration management and the justice are almost hard to adapt the requirements of intellectual property protection in the technical innovation process.

3.1.4 Technical innovation body lacks in protection strategies or the target is not practical

Many technical innovational subjects or intellectual property obliges including enterprises, colleges, graduate schools, and individuals in special conditions will not plan the acquisition, utilization, management, and protection of intellectual property in the technical innovational process. And many targets of the intellectual innovational subjects will not accord with the requirements of the times, and fall away the maximization of the economic and social benefits.

\subsubsection{The exterior protection measures are deficient in the technical innovation process}

The macro management of technical innovation or the intellectual property protection department of the state have not harmonized the intellectual property protection strategies or polices systematically and properly in time, or adjusted and confirmed these strategies or polices from the view of the benefit maximization of different right subjects or the promotion of technical innovation.

\subsection{Countermeasures of the intellectual property protection in the technical innovation process}

\subsubsection{Enhancing the strategic consciousness of intellectual property protection}

Enterprises should develop the strategic research of intellectual property surrounding the total strategic subject, and form their own core technologies or products. The patent management should run through the whole process of technical innovation, and largely enhance the ability of utilizing the patent system and the level of protecting the patent.

\subsubsection{Enhancing the management level of intellectual protection}

Combining with the practice of production and operation, the government should institute the work plan of intellectual property, and confirm the organization institution, the management responsibility, the management range, the employees' obligation, and relative legal responsibilities of the intellectual property protection work. By effective networking management, enterprises could enhance the level of whole service, including the quantity, quantity, and result transformation of intellectual property.

\subsubsection{Establishing the encouragement and limitation mechanism of intellectual property}

The government should build good enterprise development environment to encourage the innovation of science and technology, carry out the policy that the patent technology participates in the distribution as the production factor, guarantee the patent originators to obtain their own returns, and further stimulate scientific research personnel's enthusiasm. The government should also grasp the talent flow, and strengthen the management of those persons assuming the scientific research tasks, and constitute strict limitation systems. For those key technologies about the enterprises, relative enterprises can apply the secret protection of enterprise technology without the patent application, and these core technologies could be controlled dispersedly, i.e. a set of complete technology should be grasped by many individuals or organizations, and the key department should be managed in different grades to ensure the safety of the core technology.

3.2.4 Quickening the transformation speed of intellectual property results

The successful transformation of scientific results is the best protection to the intellectual property, and the final 
target of the intellectual property management. Enterprises should adopt effective measures to largely push the result transformation. The government should create interior and exterior conditions for the result transformation, and provide the opportunity for them to use their talents, and transform the scientific research result into the practical productivity.

\section{References}

Fu, Jiayi. (1998). Theory of Technical Innovation. Beijing: Tsinghua University Press.

Li, Peilin. (2008). Study on the linkage of technical innovation ability and enterprise's Intellectual property strategy. Science and Technology Management Research. No.7.

Liu, Chuntian. (2003). Intellectual Property Law. Beijing: China Renmin University Press.

Sheng, Hui. (2008). The Protective System of Intellectual Property Rights and Promoting Technical Innovation of Corporation. Technoeconomics \& Management Research. No.4.

Wang, Deying. (2008). A Study on Enterprise Technological Innovation Dynamic System Based on Intellectual Property System. Science \& Technology Progress and Policy. No.20. 